Louisiana State University

LSU Digital Commons

$4-1-2006$

\title{
Antagonisms, mutualisms and commensalisms affect outbreak dynamics of the southern pine beetle
}

\author{
Richard W. Hofstetter \\ Northern Arizona University \\ James T. Cronin \\ Louisiana State University \\ Kier D. Klepzig \\ USDA Forest Service \\ John C. Moser \\ USDA Forest Service \\ Matthew P. Ayres \\ Dartmouth College
}

Follow this and additional works at: https://digitalcommons.Isu.edu/biosci_pubs

\section{Recommended Citation}

Hofstetter, R., Cronin, J., Klepzig, K., Moser, J., \& Ayres, M. (2006). Antagonisms, mutualisms and commensalisms affect outbreak dynamics of the southern pine beetle. Oecologia, 147 (4), 679-691. https://doi.org/10.1007/s00442-005-0312-0 


\section{Antagonisms, mutualisms and commensalisms affect outbreak dynamics of the southern pine beetle}

Received: 6 May 2005/ Accepted: 4 November 2005/Published online: 2 December 2005

(C) Springer-Verlag 2005

\begin{abstract}
Feedback from community interactions involving mutualisms are a rarely explored mechanism for generating complex population dynamics. We examined the effects of two linked mutualisms on the population dynamics of a beetle that exhibits outbreak dynamics. One mutualism involves an obligate association between the bark beetle, Dendroctonus frontalis and two mycangial fungi. The second mutualism involves Tarsonemus mites that are phoretic on $D$. frontalis ("commensal"), and a blue-staining fungus, Ophiostoma minus. The presence of $O$. minus reduces beetle larval survival ("antagonistic") by outcompeting beetle-mutualistic fungi within trees yet supports mite populations by acting as a nutritional mutualist. These linked interactions potentially create an interaction system with the form of an endogenous negative feedback loop. We address four hypotheses: (1) Direct negative feedback: Beetles directly increase the abundance of $O$. minus, which reduces per capita reproduction of beetles. (2)
\end{abstract}

Electronic Supplementary Material Supplementary material is available for this article at http://dx.doi.org/10.1007/s00442-0050312-0 and is accessible for authorized users.

Communicated by Jay Rosenheim

R. W. Hofstetter $(\square)$

School of Forestry, Northern Arizona University,

Flagstaff, AZ 86011, USA

E-mail: Rich.Hofstetter@nau.edu

Tel.: + 1-928-5236452

Fax: + 1-928-5231080

J. T. Cronin

Department of Biological Sciences, Louisiana State University, Baton Rouge, LA 70803, USA

K. D. Klepzig · J. C. Moser

Southern Research Station, USDA Forest Service, Pineville, LA 71360, USA

M. P. Ayres

Department of Biological Sciences, Dartmouth College, Hanover, NH 03755, USA
Indirect negative feedback: Beetles indirectly increase mite abundance, which increases $O$. minus, which decreases beetle reproduction. (3) The effect of $O$. minus on beetles depends on mites, but mite abundance is independent of beetle abundance. (4) The effect of $O$. minus on beetles is independent of beetle and mite abundance. High Tarsonemus and O. minus abundances were strongly correlated with the decline and eventual local extinction of beetle populations. Manipulation experiments revealed strong negative effects of $O$. minus on beetles, but falsified the hypothesis that horizontal transmission of $O$. minus generates negative feedback. Surveys of beetle populations revealed that reproductive rates of Tarsonemus, O. minus, and beetles covaried in a manner consistent with strong indirect interactions between organisms. Co-occurrence of mutualisms embedded within a community may have stabilizing effects if both mutualisms limit each other. However, delays and/ or non-linearities in the interaction systems may result in large population fluctuations.

Keywords Feedback - Fungi - Mites - Mutualism · Population dynamics

\section{Introduction}

Positive interactions among species (mutualisms and commensalisms) have been generally neglected by ecologists relative to negative interactions, such as competition and predation (Crawley 1990; Dickman 1992; Kearns et al. 1998; Menge 2000; Richardson et al. 2000; Waser et al. 2000). Even though positive interactions are common, we know little about their role in population dynamics (Addicott 1986; Holland and DeAngelis 2001; Holbrook and Schmitt 2004). Most studies of mutualisms have emphasized pairwise interactions (Herre et al. 1999) even though most mutualisms are embedded within multi-species systems, which can produce a diversity of indirect effects 
(Wilson 1986; Wootton 1993; Jones et al. 1998; Stanton 2003). The potential for strong indirect effects may be especially high when the interaction system includes mutualisms, because strong positive feedback from + / + interactions should tend to propagate, or even amplify, population fluctuations that arise for any reason elsewhere in the associated community. Thus, systems that include mutualisms may be more likely to exhibit high amplitude fluctuations from exogenous effects (Dean 1983).

Pairwise interactions among species may generate reciprocal dynamics that yield endogenous demographic feedback (density-dependence, Berryman 2002). Depending on the sign $(+/-)$ and speed of feedback, populations may exhibit simple or complex dynamics (May 1976a; Turchin and Taylor 1992). Endogenous feedback could also be generated by multi-species interaction systems that form a feedback loop (Levins and Shultz 1996). If the interaction system produces density-dependent feedback with delays or nonlinearities, it would tend to generate endogenous fluctuations in populations (Lima and Jaksic 1999). Here we evaluate the effects of an interaction system that includes mutualisms, commensalisms, and antagonisms on the population dynamics of a notable outbreak bark beetle of North American pine forests.

The southern pine beetle, Dendroctonus frontalis Zimmerman (Coleoptera: Scolytinae), undergoes extreme fluctuations in abundance (Turchin et al. 1991) that result in extensive mortality of their host trees and produce broad, economically significant, patterns of forest disturbance (Price et al. 1997). Part of the temporal variance in beetle abundance is attributable to delayed density-dependence from specialist natural enemies, especially Thanasimus dubius (Coleoptera: Cleridae; Turchin et al. 1999; Cronin et al. 2000). However, D. frontalis also has strong interactions with symbiotic fungi that have been hypothesized to influence beetle population dynamics (Klepzig et al. 2001; Lombardero et al. 2000, 2003). For instance, the bluestaining fungus (Ophiostoma minus), commonly found with $D$. frontalis, competes within the phloem with other fungi that have an obligate mutualism with the beetles (Klepzig and Wilkens 1997; Klepzig et al. 2004). O. minus is introduced into phloem tissue both by adult beetles directly and by their associated mites (Tarsonemus spp., phoretic on beetles; Bridges and Moser 1983; Moser 1985; Moser and Bridges 1986). This suggests the possibility of an endogenous negative feedback loop (Fig. 1: H1, H2) in which the abundance of beetles affects $O$. minus, which affects per capita reproduction of beetles. This could be via direct effects of beetles on O. minus (Hypothesis 1) or indirect effects mediated by mites (Hypothesis 2). Alternatively, the demographic effects of $O$. minus on beetles could vary independently of beetle abundance (Fig. 1: H3, H4). In this case, the effect of $O$. minus on beetles might still depend on mite abundance, but mite abundances would be independent of beetle abundance (Hypothesis 3), resulting in no

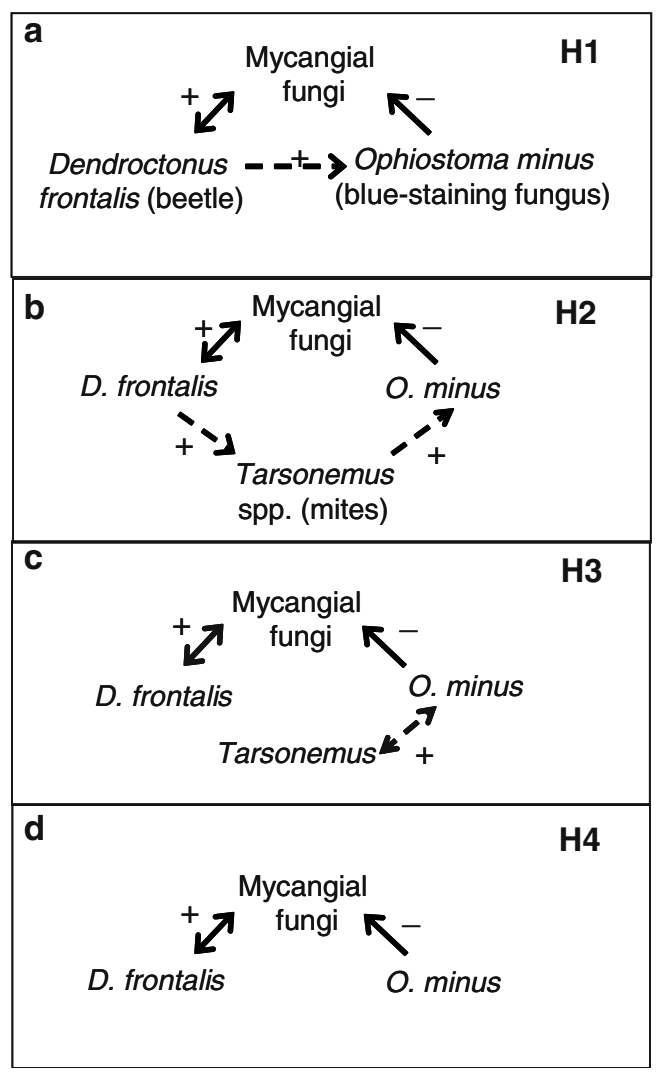

Fig. 1 Models of proposed hypotheses. Solid arrows indicate known effects of one species on the abundance of the other species, and dashed arrows indicate interactions tested in this study. The mycangial fungi and beetles ( $D$. frontalis) are obligate mutualists. Any factor that affects the mycangial fungi will influence $D$. frontalis. a $H 1$, Direct negative feedback: D. frontalis directly increase the abundance of $O$. minus, which reduces per capita reproduction of the $D$. frontalis. b $H 2$, Indirect negative feedback: beetles indirectly increase the abundance of $O$. minus by increasing the abundance of mites (Tarsonemus), generating a subsequent loss of beetle per capita reproduction. c H3, No negative feedback, but the effect of $O$. minus on $D$. frontalis depends on Tarsonemus abundance, and Tarsonemus abundance is independent of $D$. frontalis abundance. d $H 4$, No negative feedback: the effect of $O$. minus on $D$. frontalis is independent of beetle or mite abundances

negative feedback. Finally, the effect of $O$. minus on beetles might be independent of either beetle or mite abundance (Hypothesis 4).

Although the effects of $O$. minus on beetles occurs indirectly via interactions with their mycangial fungi (Goldhammer et al. 1990; Klepzig and Wilkens 1997), for the purposes of this study we have lumped beetles and their mycangial fungus together. Detailed studies of potential differential interactions between $O$. minus and mycangial fungi in beetle infestations are published elsewhere (Hofstetter et al. 2005a, b). Here, we tested for general effects of $O$. minus on beetle reproduction by manipulating the abundance of $O$. minus on beetle exoskeletons and measuring beetle reproduction. We evaluated one possible pathway for endogenous feedback $(\mathrm{H} 1)$ by including a factorial manipulation of $O$. minus inoculation levels and $D$. frontalis attack 
density. $\mathrm{H} 1$ would be supported if increasing density of parent beetles exacerbates the effect of $O$. minus on beetle reproduction (because of horizontal transmission of $O$. minus among beetle offspring within the phloem). In our experiment, this would be revealed as a statistical interaction between the density of beetles and the frequency of beetles with $O$. minus spores; i.e., if the effect of $O$. minus inoculation on per capita beetle reproduction is greatest when attack densities are high. We evaluated the role of mites $(\mathrm{H} 2-\mathrm{H} 4)$ through an experimental manipulation of phoretic mites on beetles. We were unable to experimentally manipulate both beetle density and phoretic mite density, and thus could not experimentally test $\mathrm{H} 2$. Instead, we surveyed multiple beetle populations to test for predicted correlations among $O$. minus abundance, mite abundance, and beetle reproduction. The survey was conducted with a hierarchical sampling design, which allowed us to evaluate the spatial scale of variation in the abundance of $O$. minus, mites, and beetles. If the abundance of $O$. minus and mites is strongly influenced by climate rather than by beetle density (a likely mechanism under $\mathrm{H} 3$ and $\mathrm{H} 4$ ) then variation should be high at a coarse spatial scale.

\section{Materials and methods}

\section{Study system}

Dendroctonus frontalis is a native bark beetle that inhabits pine forests in Central and North America. $D$. frontalis uses pheromones to promote mass attacks on individual trees which must be killed to permit beetle larval development (Thatcher et al. 1980). Larvae feed upon phloem tissue and mutualistic fungi (Entomocorticium sp. A or Ophiostoma ranaculosum formerly Ceratocystiopsis ranaculosus; Jacobs and Kirisits 2003) introduced by the parent beetle (Barras 1973; Bridges 1983; Ayres et al. 2000). Female beetles cultivate these fungi within specialized glandular invaginations of the prothorax (mycangia; Happ et al. 1976; Hsiau 1996). Larvae fare poorly in the absence of the mycangial fungi (Barras 1973) and the fungi only occur in association with $D$. frontalis, so this is a strong obligate mutualism. D. frontalis have 3-6 generations per year depending upon temperatures (Thatcher et al. 1980; Ungerer et al. 1999).

During epidemics, populations of $D$. frontalis occur as multiple local aggregations that are scattered through a forest landscape. These infestations are generally comprised of neighboring trees, each containing beetles in one or more stages of development (Coulson 1980). Infestations are initiated by dispersing beetles in the spring and may enlarge through the rest of the year to included hundreds to thousands of trees containing thousands to millions of beetles. The following spring, beetles disperse and initiate a new set of infestations.
A large complex of insect predators and competitors develop concurrently in the host tree (reviewed in Thatcher et al. 1980). Commensal mites (Acarina: Tarsonemidae) are also commonly associated with D. frontalis and depend on the beetles for transportation (phoresy) between trees (Bridges and Moser 1983; Moser 1985; Moser and Bridges 1986). Tarsonemus mites feed on O. minus (Lombardero et al. 2000), which is one of the so called "bluestain fungi" that are common associates of bark beetles (Solheim 1986; Perry 1991; Seifert 1993; Jacobs and Wingfield 2001). Tarsonemus spp. carry spores of $O$. minus to newly attacked trees (Leach et al. 1934; Moser et al. 1995) and propagate $O$. minus within the oviposition galleries of $D$. frontalis (Lombardero et al. 2003). O. minus spores can also be transported directly on the exoskeleton of $D$. frontalis (Barras and Perry 1975). Within the tree, O. minus grows quickly (cm per day), forming vertical elliptical patches within the phloem (where it produces a black/blue stain). Beetle larvae that develop within or near patches of $O$. minus produce uncharacteristically long tunnels and often die (Barras 1970; Goldhammer et al. 1989; Lombardero et al. 2003). The negative effect of $O$. minus on $D$. frontalis is apparently an indirect result of asymmetric competition between $O$. minus and mycangial fungi within the phloem (Klepzig 1998).

\section{Experimental manipulation of $O$. minus on beetles}

To test for interacting effects of beetle density and $O$. minus inoculation levels on beetle reproduction (Hypothesis 1), we placed replicate field cages on trees and stocked each with low, medium, or high densities of attacking adults that carried low, medium or high levels of $O$. minus inoculum. Densities corresponded to approximately $6.6,13.3$, and 19.9 beetles $/ \mathrm{dm}^{2}$, encompassing the range of densities found in nature (Fargo et al. 1979).

We manipulated the prevalence of $O$. minus by altering the fraction of $D$. frontalis that carried the fungus. Adult beetles were surface-sterilized (collected from nature) by pouring White's solution over individuals held in a screen funnel for $20 \mathrm{~s}$ (Barras 1972). This process also removed phoretic mites, except under the elytra. One half of the beetles were forced to walk for $30 \mathrm{~s}$ on agar plates containing sporulating $O$. minus fungi. The remaining beetles were placed on sterile plates for $30 \mathrm{~s}$ to control for handling procedure.

We placed screen cages on 23 healthy loblolly pine (Pinus taeda, DBH of 20-28 cm) at the edge of a beetle infestation in the Kisatchie National Forest, Louisiana. On each tree, we attached two $0.5-\mathrm{m}$ long cages centered at 3 and $5 \mathrm{~m}$ from the base of the tree, such that $1.5 \mathrm{~m}$ separated the upper from the lower cage along the bole of the tree. The distance between cages was sufficient to preclude the spread of beetle galleries or fungi between them (J.T. Cronin, unpublished data). We sealed the edges of the cage to the bark of the tree with caulk. We 
baited the trees with frontalin and turpentine to attract $D$. frontalis from the surrounding area. Once the tree was under attack, we added $D$. frontalis $(0,50$, or $100 \%$ infected with $O$. minus) to the cages $(500,1,000$, or 1,500 beetles per cage, 1:1 sex ratio). We assigned treatments at random to a cage and established five replicates for each of the nine treatment combinations.

After the attack phase was complete and D. frontalis offspring were late larvae or pupae, we cut down each tree, placed the caged sections in rearing containers, and collected and counted the $D$. frontalis offspring that subsequently emerged. After all beetles emerged, we measured the percentage of bark undersurface (phloem) that was stained blue by $O$. minus. We tested for effects of initial beetle density and $O$. minus infection on per capita reproductive success of $D$. frontalis (adult offspring produced/parental adult) with a full-factorial ANOVA. Beetle density and $O$. minus infection rate were treated as fixed factors and tree (bearing two cages each) was treated as a randomized block effect in the model. We used the same model to test for effects on the proportion of phloem area with $O$. minus. To correct for heteroscedasticity, we ln-transformed progeny/adult and arcsine-square root transformed percent $O$. тіпиs/ phloem area.

Experimental manipulation of Tarsonemus mites on beetles

To test for indirect effects of phoretic mites on beetle reproduction (via increases in area colonized by O. minus) (Hypotheses 2, 3), we conducted a factorial manipulation of phoretic mites and $O$. minus on adult beetles. We screened sections on four P. taeda at the leading edge of an infestation in the Talladega N.F., Alabama, in July 2000. We covered the bole of the tree from 3 to $5 \mathrm{~m}$ in height with a fine woven dark brown cotton cloth, and sealed the edges of the cloth to the tree with caulk and black duct tape. We initiated $D$. frontalis attacks simultaneously on the four trees using frontalure and deployed three Lindgren funnel traps (Phero Tech, Inc.) to collect flying $D$. frontalis. Beetles captured in the traps were placed individually into sterile, 1-ml centrifuge vial-caps and stored on ice. We removed all phoretic mites from beetles (averaging 0.62 mites/beetle) and stored them on a sporulating culture of $O$. minus. We placed individual beetles into a clear gelatin capsule and randomly assigned each to one of four treatment groups: Control (mites removed and no O. minus added), Mite (one mite added), O. minus (beetles walked on $O$. minusagar plate) and $O$. minus + Mite (beetles walked on $O$. minus-agar plate and one mite added). Mite treatments involved the addition of one female Tarsonemus mite (reared on $O$. minus) per beetle. For the O. minus treatments, we placed each beetle on a sporulating culture of $O$. minus for $30 \mathrm{~s}$ immediately before placing it into the tree. We did not surface-sterilize beetles with White's solution prior to infection. Isolates of $O$. minus on beetles revealed that $100 \%$ of beetles from the $O$. minus treatment and $49 \%$ of the control beetles carried O. minus.

Once each tree was under attack, we removed the brown cloth that had prevented beetles from attacking that section of the tree and divided the exposed bark into four $5 \times 5 \mathrm{dm}$ treatment areas. Each of the four treatments (Control, Mite, O. minus, O. minus + Mites) was randomly assigned to one of four treatment areas in each tree. Within each treatment area, we drilled 100 evenly spaced holes to the phloem ( $5 \mathrm{~mm}$ diameter). We placed one female beetle into each hole with the small end of a gelatin capsule sealing each exit and replaced the brown cloth. After $24 \mathrm{~h}$, we introduced two males (wild beetles with mites removed) into each hole, and replaced the brown cloth to prevent additional D. frontalis attacks and prevent the introduction of competitors and predators into the treated areas. We removed the cloth after 5 weeks (1 week prior to expected emergence of offspring). During emergence, we removed a section of bark $(2 \times 3 \mathrm{dm})$ in the center of each treatment area and measured the percent of phloem area with bluestain indicative of $O$. minus, numbers of beetle attacks (each representing one pair of parental adults), number of pupal chambers (indicating successful larval development), and total length of oviposition gallery (correlated with eggs laid; Hain 1980). We estimated Tarsonemus densities in the bark by immediately counting mites in three $1-\mathrm{cm}^{2}$ areas inside and outside bluestain patches. We estimated brood survival by counting pupal chambers relative to eggs laid (estimated as $1.6 \mathrm{~cm}$ oviposition gallery; Foltz et al. 1976). We used an ANOVA model that included treatment and tree to test for effects of $O$. minus infection and phoretic Tarsonemus on per capita reproduction of $D$. frontalis (adult offspring/parental adult), O. minus abundance in phloem (arcsine-square root transformation), and mite population size (log transformed).

Natural variation and covariation in fungi, mites and $D$. frontalis

To evaluate the role of Tarsonemus and O. minus in natural $D$. frontalis populations, we tested for correlations in species abundance predicted by each hypothesis (Fig. 1). We studied beetle infestations in three National Forests in the southeastern US: the Homochitto N.F. in western Mississippi $\left(760 \mathrm{~km}^{2}\right.$ containing loblolly pine, Pinus taeda, and shortleaf pine, P. echinata), Bankhead N.F. in the southern Appalachians of northern Alabama (720 $\mathrm{km}^{2}$ containing loblolly pine and Virginia pine, $P$. virginiana) and Oakmulgee Ranger District of Talladega N.F. in south-central Alabama $\left(620 \mathrm{~km}^{2}\right.$ containing loblolly pine and longleaf pine, P. palustris). We restricted our studies to $P$. taeda, which is the most common host of $D$. frontalis in each forest.

Within the three National Forests, we selected five discrete $D$. frontalis infestations (each involving 10-100 
host trees) for surveys of $O$. minus abundance, beetle reproductive success, and Tarsonemus densities. We selected infestations approximately at random from the population of active infestations that had been detected during regular aerial surveys of each forest by U.S.D.A., Forest Service Forest Health Protection personnel. We excluded some infestations from the pool of potential study sites because they were targeted for imminent control treatments (suppression logging). We conducted surveys during June and July of 2000 and repeated with different infestations in 2001 (except for Homochitto N.F., which lacked beetle infestations during 2001). We monitored infestation status by periodically returning and recording tree colonization patterns and number of trees killed by $D$. frontalis at each site. Infestations were observed until October of each year to determine if beetle populations continued to grow, decline or go locally extinct (i.e., no beetles on or in trees for several months).

We removed two bark samples (each $21 \times 28 \mathrm{~cm}$ ) between 3 and $4 \mathrm{~m}$ from the base of five infested trees (containing pupae and callow adult beetles) in each infestation. We chose sample trees at random from the population of trees that contained beetle pupae. For each sample, we measured the percent area with bluestain (O. minus), number of beetle attacks (each representing a pair of colonizing adults), total length of oviposition gallery, and number of emergence holes or pupal chambers (indicating offspring that completed development). Areas damaged by wood borers (Cerambycidae and Buprestidae) could not be measured in the same way and were excluded from analysis. We sampled a total of 125 trees: 5 trees $\times 5$ infestations $\times 5$ forest-years. We evaluated $O$. minus abundance, gallery density, attack density, $\ln ($ progeny/beetle), and Tarsonemus per bark area using a nested ANOVA model (JMP 5.0.1, SAS Institute Inc. 2003) that included forest-year, infestation (within forest-year), and tree (within infestation and forest-year) as random effects. We used a linear regression model to characterize the effect of $O$. minus and attack density (and interaction between $O$. minus and attack density) on progeny/beetle, gallery production/beetle, larval survival (pupae/egg), and mite density. To correct for heteroscedasticity, we transformed percent area of phloem colonized by $O$. minus (arcsine-square root) and mite abundance $[\log (x+1)]$. We computed correlations among traits (means for each infestation) using a Pearson productmoment correlation coefficient, with a Bonferroni correction to control Type I errors for the full correlation matrix.

To determine phoretic Tarsonemus abundance and fungal composition within $D$. frontalis mycangia and on $D$. frontalis exoskeletons, we captured flying adult $D$. frontalis using Lindgren funnel traps placed against trees that were under attack. We monitored three traps every 15 min until a minimum of $50 \mathrm{D}$. frontalis were captured (usually 1-3 h) within each infestation. We placed captured beetles immediately into a sterile $1 \mathrm{ml}$ centrifuge-cap vial and stored them on ice. We dissected the thorax of female beetles and mounted each mycangium on a microscope slide to identify the fungi present (Bridges 1983). After phoretic Tarsonemus were removed, we placed male $D$. frontalis and the head and abdomen of female $D$. frontalis onto selective media to determine the incidence of $O$. minus on the $D$. frontalis exoskeleton. We collected a total of 938 D. frontalis. We weighed a subset of intact female and male beetles to test for correlations between beetle mass and the presence of $O$. minus spores. We analyzed the incidence of $O$. minus on phoretic Tarsonemus or D. frontalis using a $\chi^{2}$ test that included forest-year and infestation (within forestyear) as independent variables. For parametric statistics, we transformed Tarsonemus abundance as natural log of the square root of Tarsonemus plus one.

\section{Results}

Negative affects of $O$. minus on beetle per capita reproduction

In field manipulations of beetle density and phoretic $O$. minus, per capita reproduction of beetles declined with increased presence of $O$. minus in phloem (Figs. 2, 3). Negative effects of $O$. minus on per capita reproduction of beetles were also observed when bluestain area in phloem exceeded $23 \% \quad(Y=0.89-0.038 X$ \%bluestain; $\left.r^{2}=0.40\right)$. In natural infestations, the parental replacement rate was less than 0 (progeny $<$ adults) when phloem area colonized by $O$. minus among trees exceeded 56\% (Fig. 4). Additionally, four of five infestations monitored crashed (local extinction) before September when average area colonized by $O$. minus exceeded $40 \%$ compared to only one of 20 infestations when $O$. minus coverage was below $40 \%$ (Table 1 ).

The presence of $O$. minus on beetles' exoskeletons was unrelated to beetle mass (paired $t$-test: $t_{41}=0.66$, $P=0.51)$ or to whether individual females were carrying $E$. sp. $A$ vs. $O$. ranaculosum within their mycangium (49 vs. $53 \%$, respectively). Male and female beetles were equally likely to carry $O$. minus spores on their exoskeleton ( 49 vs. $\left.51 \% ; \chi^{2}=0.37, P=0.39\right)$.

Test of direct negative feedback between beetles and O. minus

Although per capita reproduction of $D$. frontalis declined with increased presence of $O$. minus in phloem (experimental manipulation: $F_{1,32}=22.7, P<0.01$; field surveys: $r=-0.42, P<0.01, n=125)$ and density of adult beetles (experimental manipulation: $F_{2,25}=54.6$, $P<0.01$; field surveys: $r=-0.45, P<0.01$ ), increased density of adult beetles did not lead to higher abundance of $O$. minus in the phloem (manipulation study: $F_{2,25}=0.79, P=0.47 ; F_{4,25}=0.47, P=0.76$ for interac- 

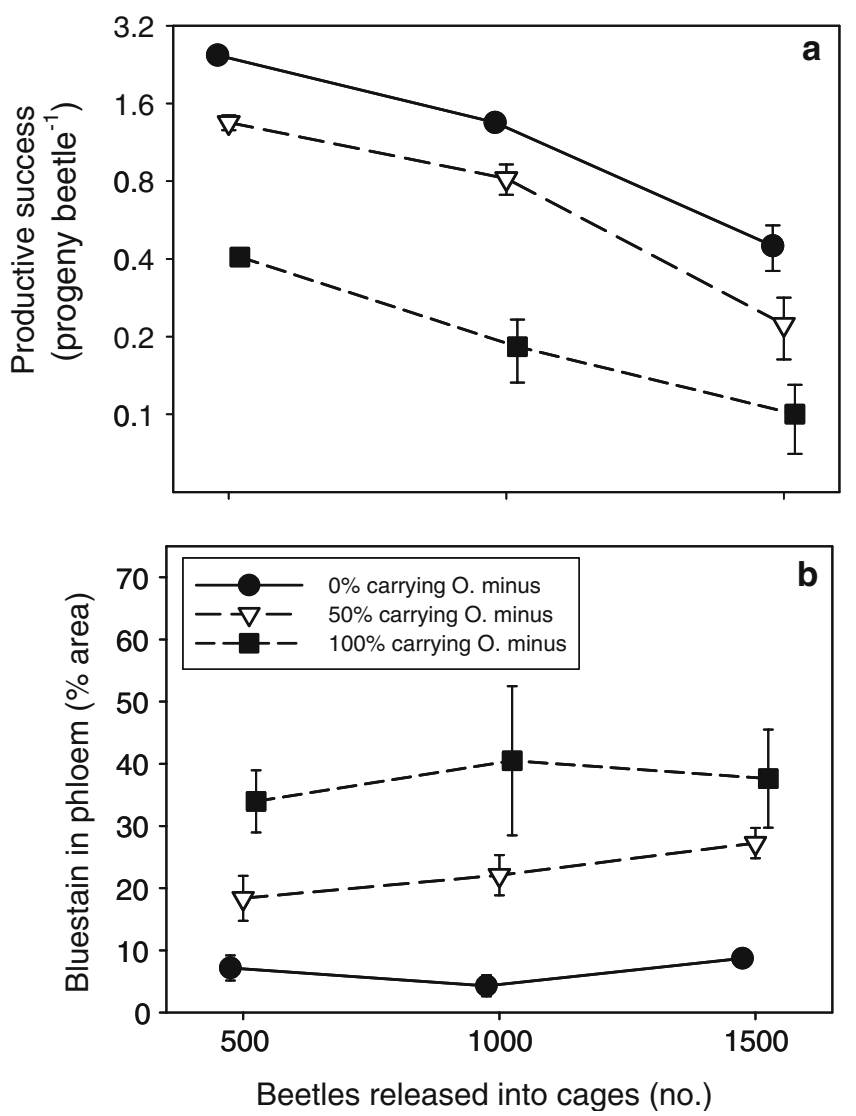

Fig. 2 The effect of $D$. frontalis beetle density and percentage of beetles carrying $O$. minus $[0$ (filled circle), 50 (unfilled inverted triangle), or 100 (filled box)] on a adult offspring per beetle and $\mathbf{b}$ the percent coverage of $O$. minus (bluestain) in phloem in the fieldcage experiment. Means \pm SE. Note log scale in a

tion of beetle density $x \%$ infected) (field surveys: $F_{1,208}=0.95, P=0.94$, Fig. 2b). In the manipulation study, the effects of density and proportion of adult beetles with $O$. minus were additive; i.e., the interaction term was small and nonsignificant $\left(F_{4,25}=0.11\right.$, $P=0.98)$, and there was no effect of tree (block effect) on per capita reproduction $\left(F_{1,25}=0.03, P=0.87\right)$. Thus, the feedback loop (H1) in which the abundance of beetles influences per capita reproduction of beetles via changes in $O$. minus is not supported. Increased proportion of colonizing $D$. frontalis carrying $O$. minus spores, independent of adult density, resulted in an increase in phloem colonized by $O$. minus (indicated by bluestain; $\left.F_{2,25}=31.8, P<0.01\right)$ and a decline in beetle per capita reproduction $\left(F_{2,25}=33.5, P<0.01\right.$, Fig. $\left.2 \mathrm{a}\right)$. However, surveys of natural infestations revealed that the frequency of beetles carrying $O$. minus and bluestain within infestations was unrelated (Fig. 5b). The percentage of beetles carrying $O$. minus spores directly on their exoskeleton ranged from 15 to $93 \%$ across infestations and varied significantly among the three national forests and infestations (Appendix B, Table 2). The frequency of $O$. minus on beetles was unrelated to any measured attribute of infestations, including the abun- dance of mites in phloem, the abundance of phoretic mites, or the percentage of female adults carrying $E$. sp. $A$ vs. the $O$. ranaculosum in their mycangium (Table 2). In addition, local beetle population size (estimated as number of infested trees) was unrelated to fungal abundance, mite abundance or beetle reproduction within infestations (Table 3, evidence against $\mathrm{H} 1$ and $\mathrm{H} 2$ ). The relative frequency of the two species of mycangial fungi within infestations was not related to percent O. minus in phloem or Tarsonemus densities (Table 3).

Test of indirect negative feedback via phoretic mites and $O$. minus

Because we did not experimentally manipulate mite densities and beetle densities together, we cannot directly test and conclude the indirect pathway from
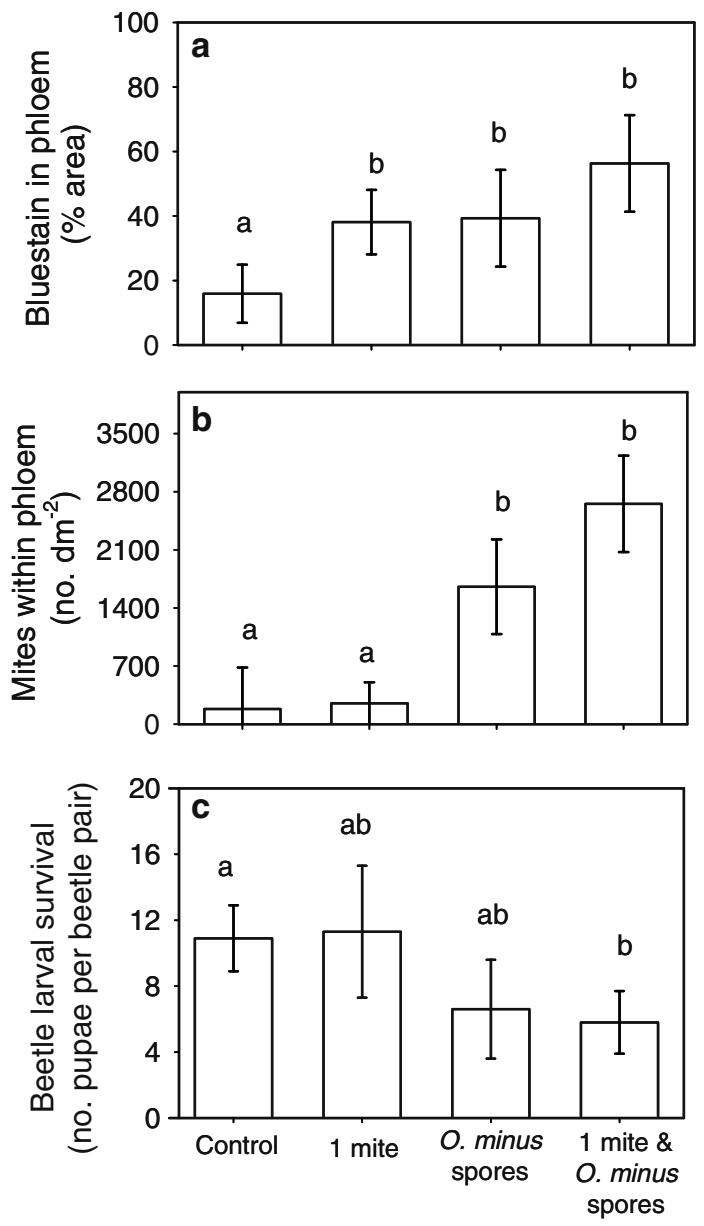

Additions to adult beetles

Fig. 3 Results from experimental additions of $O$. minus and Tarsonemus on $D$. frontalis. Bars show change $( \pm \mathrm{SE})$ relative to control beetles in a extent of bluestain (O. minus) within phloem, b abundance of mites within phloem, and $\mathbf{c}$ larval survival. Bars with different letters indicate significant difference $(P<0.05)$ between means 


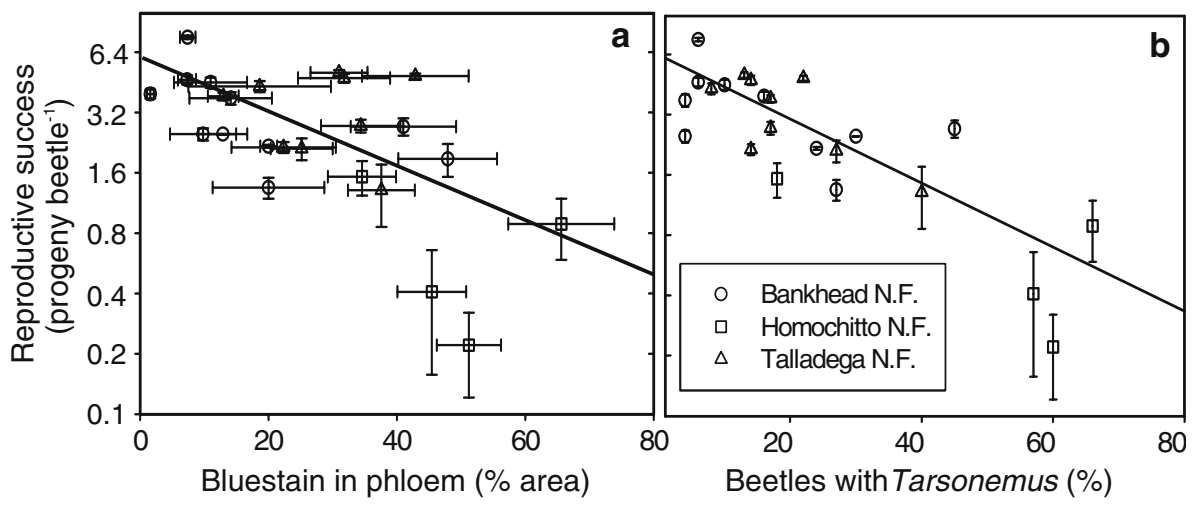

Fig. 4 Relationships between per capita reproductive success of $D$. frontalis and a percent bluestain $(O$. minus $)$ in phloem $\left(y=1.68-0.03 x, \quad P<0.01, r^{2}=0.37\right)$ and $\mathbf{b}$ percent of beetles carrying phoretic mites (Tarsonemus; $y=1.83-0.037 x, P<0.01$,

beetles to $O$. minus via mites (H2). However, our experimental additions of phoretic Tarsonemus mites to colonizing beetles resulted in an increase in $O$. minus within phloem (support for $\mathrm{H} 3$ and partial support of H2, Fig. 3, Appendix A). Surveys of natural infestations also revealed a strong correlation between phoretic Tarsonemus abundance and $O$. minus abundance within infested trees (Fig. 5a). Beetle reproduction was negatively related to phoretic Tarsonemus abundance (Fig. 4b) among infestations within forests (support for $\mathrm{H} 3$, partial support for $\mathrm{H} 2$ ), and in general, beetle per capita reproduction within infestations was less than 0 when $>50 \%$ of adult beetles carried $\geq 1$ Tarsonemus (Fig. 4b). Field surveys of natural beetle infestations revealed that average beetle attack densities within tree were positively correlated with Tarsonemus and $O$. minus in phloem $(r=0.50-0.56)$, suggesting the possibility of density-dependence but these were not quite significant with Bonferroni corrections $(0.05<P<0.10$; Table 3$)$. Dissections of field collected female beetles revealed that beetles carrying $O$. ranaculosum versus Entomocortium sp. $A$ as their mycangial fungus were more likely to carry Tarsonemus (40\% vs. $\left.29 \% ; \chi^{2}=11.6, P=0.008\right)$.

Table 1 Relationship between abundance of $O$. minus (\% phloem with bluestain) and $D$. frontalis population persistence: number of infestations that persisted (continuing attacks of live trees) or crashed (local extinction of beetles) before September of each year

\begin{tabular}{lll}
\hline $\begin{array}{l}\text { Percent phloem } \\
\text { area with bluestain }\end{array}$ & $\begin{array}{l}\text { Infestations } \\
\text { that persisted }\end{array}$ & $\begin{array}{l}\text { Infestations } \\
\text { that crashed }\end{array}$ \\
\hline $0-10$ & 4 & 0 \\
$11-20$ & 7 & 0 \\
$21-30$ & 4 & 0 \\
$31-40$ & 4 & 1 \\
$41-50$ & 1 & 2 \\
$>50$ & 0 & 2
\end{tabular}

Mean levels of $O$. minus per infestation were sampled in June $\left.r^{2}=0.54\right)$. Each symbol represents one infestation within the Bankhead (circle), Homochitto (square box), or Talladega (triangle) National Forests ( \pm SE based on five trees/infestation). Note the log scale used

Test of feedback between $O$. minus and mites, independent of beetle abundance

Tarsonemus and $O$. minus (within trees) were strongly correlated within natural infestations (Table 3, Fig. 5a) and experimentally manipulated trees (Fig. 3, support for $\mathrm{H} 3$; evidence against $\mathrm{H} 1, \mathrm{H} 4)$. For instance, average Tarsonemus densities in the phloem increased significantly following additions of $O$. minus and O. minus + Tarsonemus on attacking beetles (Fig. 3b; Student's $t, P<0.05)$. Across all natural infestations surveyed, $28 \%$ of flying beetles carried Tarsonemus and $69 \%$ percent of the phoretic Tarsonemus carried O. minus ascospores, averaging 18 ascospores per mite. Both O. minus and Tarsonemus were present in all 24 infestations surveyed and were positively correlated (Table. 2, 3). Also given that the abundance of O. minus and Tarsonemus were highly variable among and across forests (Appendix B, Table 1), there is little evidence that $O$. minus abundance functions independent of Tarsonemus (evidence against $\mathrm{H} 4$ ).

\section{Discussion}

Demographic effects of $O$. minus and Tarsonemus on $D$. frontalis

Dendroctonus frontalis undergoes extreme fluctuations in abundance (Turchin et al. 1991). Results here indicate that variation in abundance of symbiotic associates is a meaningful driver of variation in beetle population dynamics. In our study, the abundances of $O$. minus and Tarsonemus explained $37-54 \%$ of the variation in beetle reproduction among infestations (Fig. 4). Across 20-25 natural infestations, O. minus ranged from 2 to $65 \%$ of bark and Tarsonemus ranged from 0.1 to 7.1 per beetle. The apparent demographic consequences for $D$. frontalis are equal or greater than 

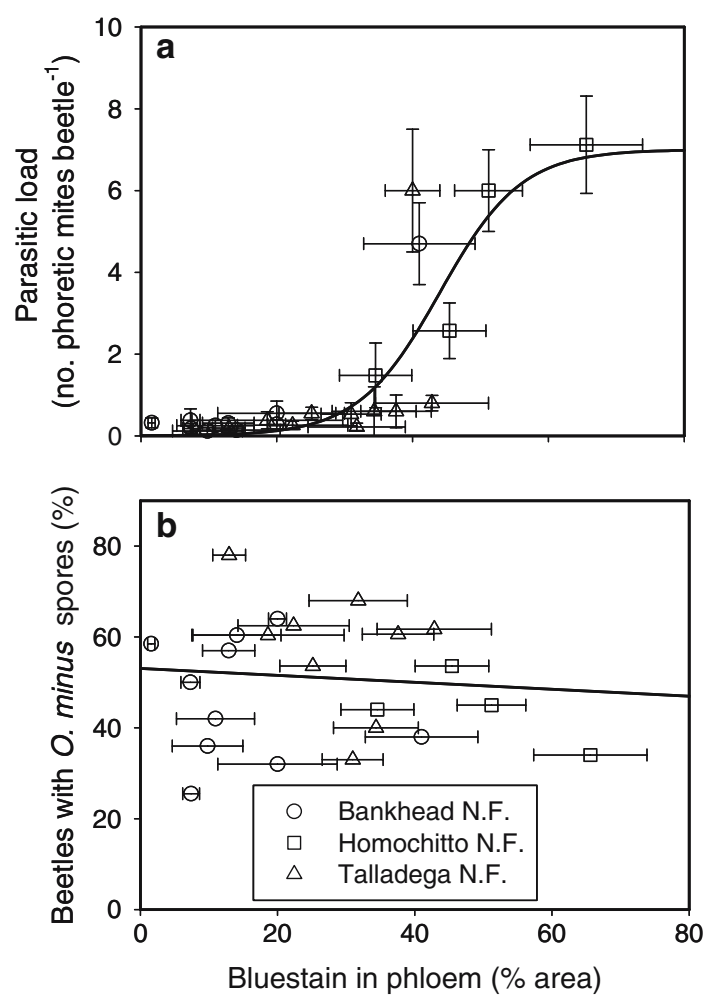

Fig. 5 Relationships between $O$. minus in phloem and a phoretic mites/beetle $\left.\left(y=7 / \mathrm{e}^{-(x-44 / 6)}\right) x, P<0.01, r^{2}=0.74\right)$ and $\mathbf{b}$ percent of adult $D$. frontalis (phoretic mites removed) with $O$. minus spores on their exoskeleton $\left(y=53-0.048 x, P<0.68, r^{2}=0.00\right)$. Each symbol represents one infestation within the Bankhead (circle), Homochitto (square box), or Talladega (triangle) National Forests ( $\pm \mathrm{SE}$ based on five trees per infestation)

other known sources of mortality. For example, an increase from 8 to $49 \%$ in average extent of 0 . minus in phloem corresponds to an $85 \%$ decline in progeny per beetle (Fig. 4a). In comparison, high densities of predators reduce survival of $D$. frontalis by $60 \%$, and reduce the ratio of increase $\left(N_{t}: N_{t-1}\right)$ by $50-70 \%$
(Reeve 1997; Turchin et al. 1999; Reeve and Turchin 2002).

The negative effect of $O$. minus on beetles is believed to be indirect, as indicated in Fig. 1, because we know that (1) there is strong asymmetric competition between mycangial fungi and $O$. minus (Klepzig 1998); (2) D. frontalis larvae require mycangial fungi (Barras 1973); and (3) non-mycomutualistic beetles seem to be less affected by phoretically vectored bluestain fungi (Yearian et al. 1972; Klepzig and Six 2004). However, we cannot exclude the possibility of allelopathic effects from phenolics and isocoumarins elicited by the tree in response to $O$. minus, or by melanin produced by O. minus (Hemingway et al. 1977; DeAngelis et al. 1986).

Regardless of the mechanism, recognition of demographic effects of $O$. minus may have value for management of pestilence from $D$. frontalis. For example, monitoring the abundance of Tarsonemus or O. minus within infestations may be a tool for predicting beetle population trends (Table 1). It is even possible that $O$. minus could be deployed as a biological control agent for D. frontalis. Abundances of $O$. minus and Tarsonemus can be enhanced within natural infestations though the use of baited open-exit Lindgren traps (R.W. Hofstetter et al., unpublished), but there remain technical challenges to operational use.

Variation among infestations in $O$. minus abundance appears to be driven much more strongly by the association between $O$. minus and phoretic mites $(r=0.74-0.80$; Table 3$)$ than by the association between $O$. minus and $D$. frontalis $(r=-0.06)$. Furthermore, even with large experimental additions of $O$. minus spores to beetles, O. minus in the absence of Tarsonemus did not reach levels observed in natural infestations (Fig. 4). This survey, in combination with results from experimental manipulation of Tarsonemus on beetles (Table 3, Fig. 3, and Lombardero et al. 2003), suggest that Tarsonemus are a key factor for $O$. minus abundance and may be necessary for $O$. minus to reach levels high enough ( $>45 \%$ of phloem) to curtail beetle population

Table 2 Mean attributes of $D$. frontalis infestations in each National Forest and year (sampled between May and July)

\begin{tabular}{|c|c|c|c|c|c|}
\hline & Homochitto 2000 & Talladega 2000 & Talladega 2001 & Bankhead 2000 & Bankhead 2001 \\
\hline$\%$ bluestain in phloem ${ }^{a}$ & $49 \pm 6 a$ & $26 \pm 5 b$ & $34 \pm 3 b$ & $8 \pm 2 c$ & $30 \pm 6 b$ \\
\hline D. frontalis attacks $/ \mathrm{dm}^{2}$ & $7.3 \pm 0.5 \mathrm{a}$ & $5.0 \pm 0.3 b$ & $5.3 \pm 0.1 b$ & $5.6 \pm 0.4 \mathrm{bc}$ & $6.7 \pm 0.3 \mathrm{ac}$ \\
\hline $\ln$ (pupae/adult $D$. frontalis) & $-0.52 \pm 0.42 \mathrm{a}$ & $1.34 \pm 0.15 b c$ & $0.91 \pm 0.28 b$ & $1.44 \pm 0.15 \mathrm{c}$ & $0.66 \pm 0.18 b$ \\
\hline $\mathrm{Cm}$ D. frontalis gallery $/ \mathrm{dm}^{2}$ & $85 \pm 7$ & $77 \pm 4$ & $87 \pm 5$ & $84 \pm 3$ & $89 \pm 5$ \\
\hline Tarsonemus $/ \mathrm{dm}^{2}$ a & $241 \pm 31 \mathrm{a}$ & $281 \pm 54 \mathrm{a}$ & $189 \pm 40 \mathrm{ab}$ & $240 \pm 38 \mathrm{a}$ & $71 \pm 19 b$ \\
\hline Tarsonemus/D. frontalis ${ }^{\mathrm{a}}$ & $3.7 \pm 1.7 \mathrm{a}$ & $0.3 \pm 0.1 b$ & $1.8 \pm 1.1 \mathrm{c}$ & $0.2 \pm 0.1 b$ & $1.2 \pm 0.8 \mathrm{c}$ \\
\hline$\%$ D. frontalis $\mathrm{w} /$ Tarsonemus ${ }^{\mathrm{a}}$ & $45 \pm 9 \mathrm{a}$ & $15 \pm 2 b$ & $29 \pm 5 a$ & $8 \pm 2 b$ & $27 \pm 5 a$ \\
\hline$\%$ D. frontalis $\mathrm{w} / O$. minus $\mathrm{b}$ & $42 \pm 4 a$ & $66 \pm 3 b$ & $55 \pm 5 \mathrm{ab}$ & $45 \pm 3 a$ & $48 \pm 3 a$ \\
\hline$\%$ D. frontalis $\mathrm{w} /$ Ent. fungus & $50 \pm 26$ & $51 \pm 9$ & $46 \pm 8$ & $60 \pm 6$ & $60 \pm 17$ \\
\hline$\%$ D. frontalis $\mathrm{w} /$ Ent. and O.r. & $17 \pm 11 \mathrm{ab}$ & $10 \pm 4 \mathrm{a}$ & $12 \pm 5 \mathrm{ab}$ & $21 \pm 3 b$ & $13 \pm 5 \mathrm{ab}$ \\
\hline
\end{tabular}

Standard errors based on $N=5$ infestations/forest-year. Different letters indicate significant difference $(P<0.05)$ among forest-years. Bluestain indicated the presence of Ophiostoma minus, which is mutualistic with mites (Tarsonemus spp). Entomocorticium sp. A. (Ent.) and Ophiostoma ranaculosum (O.r.) are mutualistic fungi associated with D. frontalis

${ }^{a}$ Statistically analyzed with transformed data: $\log (\operatorname{sqrt}($ Tarsonemus $/$ D. frontalis $)+1)$; $\operatorname{arcsine} \operatorname{sqrt}(\%$ O. minus $) ; \log ($ Tarsonemus +1$)$, sqrt $(\%$ D. frontalis with Tarsonemus $)$

${ }^{\mathrm{b}}$ Only included propagules directly on beetle; excludes spores carried by phoretic mites 
Table 3 Correlations among $D$. frontalis infestations $(n=20-25)$ in three National Forests

\begin{tabular}{|c|c|c|c|c|c|c|c|c|c|c|}
\hline & $\begin{array}{l}\% \text { blue- } \\
\text { stain }\end{array}$ & $\begin{array}{l}\text { beetles/ } \\
\mathrm{dm}^{2}\end{array}$ & $\begin{array}{l}\ln (\text { pupae/ } \\
\text { beetle) }\end{array}$ & $\begin{array}{l}\text { gallery/ } \\
\text { attack }\end{array}$ & $\begin{array}{l}\text { gallery/ } \\
\mathrm{dm}^{2}\end{array}$ & / mites/ & $\begin{array}{l}\text { mites/ } \\
\text { beetle }\end{array}$ & $\begin{array}{l}\% \text { beetles } \\
E \text {. sp A }\end{array}$ & $\begin{array}{l}\% \text { beetles } \\
\text { O. minus }\end{array}$ & $\begin{array}{l}\% \text { beetles } \\
\mathrm{w} / \text { mites }\end{array}$ \\
\hline D. frontalis attacks $/ \mathrm{dm}^{2}$ & 0.56 & & & & & & & & & \\
\hline $\mathrm{Cm}$ D. frontalis gallery $/ D$. frontalis attack & -0.19 & $-0.77 * *$ & $0.68^{*}$ & & & & & & & \\
\hline $\mathrm{cm} D$. frontalis gallery $/ \mathrm{dm}^{2}$ & 0.32 & 0.25 & 0.06 & 0.26 & & & & & & \\
\hline Tarsonemus $/ \mathrm{dm}^{2}$ & 0.58 & -0.06 & 0.01 & 0.04 & 0.06 & & & & & \\
\hline$\%$ D. frontalis with $O$. minus & -0.06 & -0.27 & 0.06 & 0.14 & -0.37 & 0.03 & -0.13 & -0.24 & & \\
\hline$\%$ D. frontalis with Tarsonemus & $0.74 * *$ & 0.50 & $-0.82 * *$ & -0.26 & 0.33 & -0.16 & $0.75 * *$ & -0.29 & -0.06 & \\
\hline $\begin{array}{l}\text { D. frontalis population size } \\
\text { (no. infested trees) }\end{array}$ & -0.20 & -0.18 & 0.34 & 0.37 & 0.22 & 0.06 & -0.31 & -0.19 & 0.10 & -0.18 \\
\hline
\end{tabular}

$* P<0.05 ; * * P<0.01$ (with Bonferroni correction)

growth (Fig. 4). Apparently, Tarsonemus propagate $O$. minus both by transporting ascospores into newly attacked trees $(69 \%$ of phoretic mites carried an average of 18 ascospores per mite) and by dispersing existing $O$. minus within the phloem of attacked trees (Lombardero et al. 2003). Tarsonemus presumably propagates O. minus because it feeds on it (Lombardero et al. 2000). Because Tarsonemus feeds on $O$. minus, it is logical that the addition of $O$. minus leads to an increase in mites (Fig. 3), and that infestations with high $O$. minus abundances have high mites $/ \mathrm{dm}^{2}$ within phloem (Table 3). In any case, Tarsonemus, O. minus, and beetle reproduction covary in a manner consistent with a system of strong direct and indirect interactions (i.e., mites to $O$. minus to mycangial fungi to beetles; support of $\mathrm{H} 3$; Table 3).

Negative feedback or exogenous dynamics?

Do the demographic effects of $O$. minus on beetles tend to increase with increasing abundance of beetles $(\mathrm{H} 1$, $\mathrm{H} 2$ ) or is $O$. minus best regarded as an exogenous force in beetle population dynamics (H3, H4)? Because interactions between $O$. minus inoculation per beetle and beetle attack densities were not evident (Fig. 2), our studies falsified the hypothesis (H1) that horizontal transmission of $O$. minus produces negative demographic feedback. Furthermore, beetle infestation size was unrelated to $O$. minus or Tarsonemus mite abundance (Table 3, lack of support for H1, H2). Our studies give the greatest support to $\mathrm{H} 3$, that the effect of $O$. minus on D. frontalis depends on Tarsonemus abundance, but Tarsonemus abundance is independent of $D$. frontalis population size. There is a suggestion of higher $O$. minus and Tarsonemus abundance within trees that had high beetle attack densities, but tree-specific attack densities were unrelated to infestation size (Table 3), so this seems unlikely to produce densitydependence at the population scale (Berryman 2002). The hypotheses of density-dependence feedback requires that changes in beetle populations from low to high somehow generate increases in the effects of $O$. minus on per capita reproduction of beetles. Positive correlations between mites, $O$. minus, and beetle densities within trees (Table 3) give support for frequency-dependent feedback via mites, $O$. minus, and beetles. Because beetle densities within trees are a function of beetle attack rate, attack behavior, tree susceptibility, and not necessarily population size (Coulson 1980), endogenous feedback may instead occur in relation to the rate of growth of the infested area (related to beetle density within trees) rather than total beetle abundance.

A key question is whether increasing abundance of beetles, leads to increases in the abundance of phoretic mites per beetle. We have strong evidence that increases in Tarsonemus lead to increases in O. minus (Fig. 3) and beetle decline (Fig. 4; Hypothesis 3), however the connections between beetle abundances and phoretic mite abundance remain to be tested. Factorial manipulations of phoretic mites and beetle densities could be used to test whether populations of phoretic mites grow more with high beetle densities. Another possible mechanism for endogenous feedback follows from the new observation reported here that Tarsonemus are more common on beetles that harbor $O$. ranaculosum instead of $E$. sp. $A$ as their mycangial fungus. This could be because $O$. ranaculosum but not $E$. sp. $A$ is nutritionally suitable for Tarsonemus (Lombardero et al. 2000). The vast majority of Tarsonemus within infested trees are found feeding in patches of $O$. minus, but $O$. ranaculosum might provide critical nutrition for mites during the days immediately following beetle attack when $O$. minus is not well established (Lombardero et al. 2000). The proportion of female beetles harboring $O$. ranaculosum versus $E$. sp. $A$ has been reported to vary among populations (Bridges 1983), however seasonal surveys of fungi among $D$. frontalis infestations reveal no correlation between $O$. minus and either mycangial fungus (Hofstetter et al. 2005a). If beetle abundance tends to affect the proportion of mycangial fungi within a population, it is very plausible that this would generate a 
pathway of endogenous feedback (change in mycangial species leads to change in mite abundance which leads to change in $O$. minus abundance and change in beetle population growth). Beetle populations that predominantly carry $O$. ranaculosum (rather than $E$. sp. $A$ ) may be particularly affected by increases in $O$. minus because larvae feeding on $O$. ranaculosum are believed to be more susceptible to antagonistic effects of $O$. minus (Goldhammer et al. 1990), however we found no correlation between the relative abundance of each mycangial fungus and $O$. minus (Tables 2,3 ).

During epidemic outbreaks of beetles, such as were studied here, Tarsonemus and $O$. minus appear to exert their effects on beetles independently of beetle density (H3). High variation and co-variation in $O$. minus and Tarsonemus among forests suggests that climatic effects or some other coarse-grained environmental feature have important effects on the abundance of mites and fungi. Climatic patterns have been proposed to affect beetle populations through a variety of mechanisms (Craighead 1925; Kalkstein 1976; Ungerer et al. 1999; but see Turchin et al. 1991). Lombardero et al. (2003) suggested that differences between Tarsonemus and $D$. frontalis in their development rate as a function of temperature might make the community of mites, fungi, and beetles responsive to climatic variation. This is a plausible but untested hypothesis for the broad spatial autocorrelation between the abundance of mites and O. minus (Table 1).

Complex interactions within the $D$. frontalis community

The relationship between $O$. minus and $D$. frontalis is not easily classified within the normal framework of species interactions. $O$. minus is an obligate symbiont of bark beetles, chiefly $D$. frontalis in the southeastern US. $O$. minus requires $D$. frontalis for transport from recently killed trees to freshly attacked trees. Persistence of $O$. minus requires that this cycle be repeated every beetle generation (3-6 times per year). Also, O. minus appears to be generally incapable of killing trees by itself (Eckhardt et al. 2004; Wullschlager et al. 2004) and so depends upon mass attack by the beetles for breaking down tree defenses. Thus, O. minus depends upon $D$. frontalis, but is also a strong antagonist (Figs. 2, 3, 4). This is a $+/-$ relationship but differs from normal host/ parasite or predator/prey systems because the negative effects are from competition (for phloem) and the positive effects are from transport and aid in overwhelming tree defenses. Symbiotic associations between bark beetles and Ophiostomatoid fungi are common, but most cases are regarded as $+/ 0$ relations, where the beetle experiences minimal effects, or $+/+$ relations where the beetles gain nutritional benefits or assistance in killing the host tree (Berryman 1972; Clark and Richmond 1977; Strobel and Lanier 1981; Owen et al. 1987; Krokene and Solheim 1998; Six and Paine 1998; Kopper et al. 2004). Why $O$. minus is a strong antagonist of the beetles on which it depends is somewhat puzzling. One possibility is that this is a transient, evolutionarily unstable, association. Both species are presumed to have been present in the southeastern US throughout the Holocene at least, so it is not transient on the scale of decades to centuries, but $O$. minus is rare in the putatively ancestral populations of $D$. frontalis in Mexico (Moser and Macias-Samano 2000). So it may be a transient condition on the scale of millennia. Also, there may be a parallel with vector-borne parasites. Biotic vectors are hypothesized to contribute to the evolutionary maintenance of virulence in parasites (Ewald 1995). If so, other examples of antagonistic effects of fungi on their insect vectors may be found in systems where phoretic mites are important intermediates in transport of fungi.

Our surveys of natural infestations reinforce earlier suggestions that there is a strong mutualism between O. minus and Tarsonemus (Moser 1985; Lombardero et al. 2000). The persistence of mutualisms is a long-standing puzzle in community ecology because simple models of $+/+$ interactions are intrinsically unstable (May 1982). One potentially general resolution is that the persistence of mutualisms in nature depends upon broader community interactions (Ringel et al. 1996). Our system suggests a special case of how that could occur. The community includes two pairs of mutualists (beetlesmycangial fungi and mites-O. minus), and the patterns of co-occurrence between the mutualists are so strong that each pair could each be thought of as one ecological module. Thus, the system represented in Fig. 1 could be abstracted to two modules (beetles-mycangial fungi and mites-O. minus) with a $-/-$ or $+/-$ relationship (depending on the relative strength of benefits from beetles vs. competition from mycangial fungi). Stability of $-/-$ or $+/-$ interactions is relatively easy to explain compared to mutualisms (May 1976b). Thus multiple mutualisms embedded within a community could be stable if the mutualisms limit each other. However, if there are nonlinearities or delays in the feedback system between mutualist pairs, the community could have a tendency for large population fluctuations, such as we see in $D$. frontalis.

Acknowledgements We thank Matt Babineau, Dan Braden, Julia Brant, Debbie Cronin, Johnny Fryar, Dan Hogan, Karen London, Sharon Martinson, Jason Moan, Chris Steiner, Erich Vallery, Jessica Veysey and Tiina Ylioja for their assistance in the field and laboratory. Thanks to the researchers and staff at the US Forest Service in Pineville LA, and Bankhead, Homochitto and Oakmulgee Ranger Districts. The manuscript benefited from comments by Anurag Agrawal, Bill Mattson, Mark McPeek, David Peart, and Tiina Yliola. Research was supported by the US Forest Service, NRI CGPs \#9835302, \#2001-35302-09921, Dartmouth College Graduate Fellowship to R.W. Hofstetter, and National Science Foundation grant DEB 950923 to P. Turchin and J. D. Reeve. 


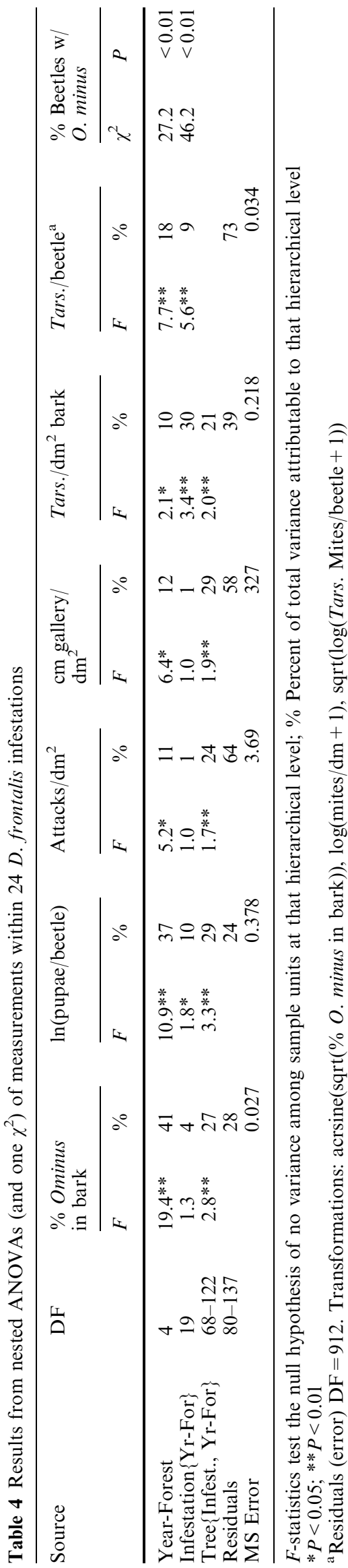

\section{Appendix B}

Table 4

\section{References}

Addicott JF (1986) On the population consequences of mutualism. In: Diamond J, Case T (eds) Community ecology. Harper and Row, New York, pp 425-436

Ayres MP, Wilkens RT, Ruel JJ, Lombardero MJ, Vallery E (2000) Nitrogen budgets of phloem feeding bark beetles with and without symbiotic fungi (Coleoptera: Scolytidae). Ecology $81: 2198-2210$

Barras SJ (1970) Antagonism between Dendroctonus frontalis and the fungus Ceratocystis minor. Annu Entomol Soc Am 63:11871190

Barras SJ (1972) Improved White's solution for surface sterilization of pupae of Dendroctonus frontalis. J Econ Entomol 65:1504

Barras SJ (1973) Reduction of progeny and development in the southern pine beetle following removal of symbiotic fungi. Can Entomol 105:1295-1299

Barras SJ, Perry TJ (1975) Interrelationships among microorganisms, bark or ambrosia beetles, and woody plant tissue: an annotated bibliography, 1965-1974. USDA Forest Service, Southern Forest Experiment Station, Gen Tech Report SO-10

Berryman AA (1972) Resistance of conifers to invasion of bark beetle-fungus associations. BioScience 22:598-602

Berryman AA (2002) Populations: a central concept for ecology? Oikos 97:439-442

Bridges JR (1983) Mycangial fungi of Dendroctonus frontalis (Coleoptera: Scolytidae) and their relationship to beetle population trends. Environ Entomol 12:858-861

Bridges JR, Moser JC (1983) Role of two phoretic mites in transmission of bluestain fungus, Ceratocystis minor. Ecol Entomol 8:9-12

Clark EW, Richmond JA (1977) Variations of free and triglyceride fatty acids in phloem of Pinus taeda infected by Ceratocystis minor. Turrialba 27:377-383

Coulson RN (1980) Population dynamics. In: Thatcher RC, Searcy J, Coster J, Hertel G (eds) The southern pine beetle. USDA Tech Bull 1631, pp 71-105

Craighead FC (1925) Bark beetle epidemics and rainfall deficiency. J Econ Entomol 18:557-586

Crawly MJ (1990) The population dynamics of plants. Phil Trans R Soc Lond B Biol Sci 330:125-140

Cronin JT, Reeve JD, Wilkens R, Turchin P (2000) The pattern and range of movement of a checkered beetle predator relative to its bark beetle prey. Oikos 90:127-138

Dean AM (1983) A simple model of mutualism. Am Nat 121:409417

DeAngelis JD, Hodges JD, Nebeker TE (1986) Phenolic metabolies of Ceratocystis minor from laboratory cultures and their effects on transpiration in loblolly pine seedlings. Can J Bot 64:151155

Dickman CR (1992) Commensal and mutualistic interactions among terrestrial vertebrates. Trends Ecol Evol 7:194-197

Eckhardt LG, Jones JP, Klepzig KD (2004) Pathogenicity of Leptographium species associated with loblolly pine decline. Plant Dis 88:1174-1178

Ewald P (1995) The evolution of virulence: a unifying link between parasitology and ecology. J Parasitol 81:659-669

Fargo WS, Coulson RN, Gagne JA, Foltz JL (1979) Correlation of southern pine beetle attack density, oviposition, and generation survival with host tree characteristics and preceding beetle life stage within the host. Environ Entomol 8:624-628

Foltz JL, Mayyasi AM, Hain FP, Coulson RN, Martin WC (1976) Egg-gallery length relationship and within-tree analysis for southern pine beetle, Dendroctonus frontalis. Zimm (Coleoptera: Scolytidae). Can Entomol 108:341-352 
Goldhammer DS, Stephen FM, Paine TD (1989) Average radial growth rate and chlamydospore production of Ceratocystis minor, Ceratocystis minor var. barrasii, and SJB 122 in culture. Can J Bot 67:3498-3505

Goldhammer DS, Stephen FM, Paine TD (1990) The effect of the fungi Ceratocystis minor Hunt, Ceratocystis minor. Hunt var Barrasii Taylor, and SJB 122 on reproduction of the southern pine beetle, Dendroctonus frontalis Zimmerman (Coleoptera: Scolytidae). Can Entomol 122:407-418

Hain FP (1980) Sampling and predicting population trends. In: Thatcher RC, Searcy J, Coster J, Hertel G (eds) The southern pine beetle. USDA Tech Bull 1631, pp 107-135

Happ GM, Happ CM, Barras SJ (1976) Bark beetle-fungal symbiosis. II. Fine structure of a basidiomycetous ecosymbiont of the southern pine beetle. Can J Bot 54:1049-1062

Hemingway RW, McGraw GW, Barras SJ (1977) Polyphenols in Ceratocystis minor infected Pinus taeda: Fungal metabolites, phloem and xylem phenols. Agric Food Chem 25:717-722

Herre EA, Knowlton N, Mueller UG, Rehner SA (1999) The evolution of mutualisms: exploring the paths between conflict and cooperation. Trends Ecol Evol 14:49-53

Hofstetter RW, Klepzig KD, Moser JC, Ayres MP (2005a) Seasonal dynamics of mites and fungi and their interaction with southern pine beetle. Env Ent (in press)

Hofstetter RW, Mahfous J, Klepzig KD, Ayres MP (2005b) Effects of tree phytochemistry on the interactions between endophloedic fungi associated with the southern pine beetle. J Chem Ecol 31:551-572

Holbrook SJ, Schmitt RJ (2004) Population dynamics of a damselfish: effects of a competitor that also is an indirect mutualist. Ecology 85:979-985

Holland JN, DeAngelis DL (2001) Population dynamics and the stability of obligate pollination mutualisms. Oecologia 126:575586

Hsiau PTW (1996) The taxonomy and phylogeny of the mycangial fungi from Dendroctonus brevicomis and Dendroctonus frontalis (Coleoptera: Scolytidae). Dissertation, Iowa State University, Ames, Iowa

Jacobs K, Wingfield MJ (2001) Leptographium Species: tree pathogens, insect associates and agents of blue-stain. American Phytopathological Society Press, St Paul

Jacobs K, Kirisits T (2003) Ophiostoma kryptum sp. nov. from Larix decidua and Picea abies in Europe, similar to $O$. minus. Mycol Res 107:1231-1242

Jones CG, Ostfeld RW, Richard MP, Schauber EM, Wolff JO (1998) Chain reactions linking acorns to gypsy moth outbreaks and Lyme disease risk. Science 279:1023-1026

Kalkstein LS (1976) Effects of climatic stress on outbreaks of the southern pine beetle. Environ Entomol 5:653-658

Kearns CA, Inouye DW, Waser NM (1998) Endangered mutualisms: the conservation of plant-pollinator interactions. Annu Rev Ecol Syst 29:83-112

Klepzig KD (1998) Competition between a biological control fungus, Ophiostoma piliferum, and symbionts of the southern pine beetle. Mycologia 90:69-75

Klepzig KD, Wilkens RT (1997) Competitive interactions among symbiotic fungi of the southern pine beetle. Appl Environ Microbiol 63:621-627

Klepzig KD, Moser JC, Lombardero MJ, Hofstetter RW, Ayres MP (2001) Symbiosis and competition: complex interactions among beetles, fungi, and mites. Symbiosis 30:83-96

Klepzig KD, Flores-Otero J, Hofstetter RW, Ayres MP (2004) Effects of available water on growth and competition of southern pine beetle associated fungi. Mycol Res 108:183-188

Klepzig KD, Six DL (2004) Bark beetle-fungal symbiosis: context dependency in complex associations. Symbiosis 37:189-205

Kopper BJ, Klepzig KD, Raffa KF (2004) Components of antagonism and mutualism in Ips pini-fungal interactions: relationship to a life history of colonizing highly stressed and dead trees. Environ Entomol 33:28-34
Krokene P, Solheim H (1998) Pathogenicity of four blue-stain fungi associated with aggressive and nonaggressive bark beetles. Phytopathology 88:39-44

Leach JG, Orr LW, Christensen C (1934) The interrelationships of bark beetles and blue-staining fungi in felled Norway pine timber. J Agric Res 49:315-342

Levins R, Schultz BB (1996) Effects of density dependence, feedback and environmental sensitivity on correlations among predators, prey and plant resources: models and practical implications. J Anim Ecol 65:802-812

Lima M, Jaksic FM (1999) Population dynamics of three Neotropical small mammals: time series models and the role of delayed density-dependence in population irruptions. Aust $\mathrm{J}$ Ecol 24:25-34

Lombardero MJ, Klepzig KD, Moser JC, Ayres MP (2000) Biology, demography and community interactions of Tarsonemus (Acrina: Tarsonemidae) mites phoretic on Dendroctonus frontalis (Coleoptera: Scolytidae). Agric For Entomol 2:193-202

Lombardero MJ, Ayres MP, Hofstetter RW, Moser JC, Klepzig KD (2003) Strong indirect interactions of Tarsonemus mites (Acrina: Tarsonemidae) and Dendroctonus frontalis (Coleoptera: Scolytidae). Oikos 102:243-252

May RM (1976a) Simple mathematical models with very complicated dynamics. Nature 261:459-467

May RM (1976b) Theoretical ecology: principles and applications. Blackwell, Oxford

May RM (1982) Mutualistic interactions among species. Nature 296:803-804

Menge BA (2000) Testing the relative importance of positive and negative effects on community structure. Trends Ecol Evol 15:46-47

Moser JC (1985) Use of sporothecia by phoretic Tarsonemus mites to transport ascospores of coniferous bluestain fungi. Trans $\mathrm{Br}$ Mycol Soc 84:750-753

Moser JC, Bridges JR (1986) Tarsonemus (Acarina: Tarsonemidae) mites phoretic on the southern pine beetle (Coleoptera: Scolytidae): attachment sites and numbers of bluestain (Ascomycetes: Ophiostomataceae) ascospores carried. Proc Entomol Soc Wash 88:297-299

Moser JC, Perry TJ, Bridges JR, Yin H-F (1995) Ascospore dispersal of Ceratocystiopsis ranaculosus, a mycangial fungus of the southern pine beetle. Mycologia 87:84-86

Moser JC, Macias-Samano JE (2000) Tarsonemid mite associates of Dendroctonus frontalis (Coleoptera: Scolytidae): implications for the historical biogeography of $D$. frontalis. Can Entomol 132:765-771

Owen DR, Lindahl KQ, Wood DL (1987) Pathogenicity of fungi isolated from Dendroctonus valens, D. brevicomis and D. ponderosae to ponderosa pine seedlings. Phytopathology 77:631-636

Perry TJ (1991) A synopsis of the taxonomic revisions in the genus Ceratocystis including a review of blue-staining species associated with Dendroctonus bark beetles. Gen Tech Report SO-86, New Orleans, LA

Price TS, Dogget HC, Pye JM, Smith B (1997) A history of southern pine beetle outbreaks in the southeastern US. Georgia Forestry Commission, Macon

Reeve JR (1997) Predation and bark beetle dynamics. Oecologia 112:48-54

Reeve JR, Turchin P (2002) Evidence for predator-prey cycles in a bark beetle. In: Berryman AA (ed) Population cycles the case for trophic interactions. Oxford University Press, New York, pp 92-108

Richardson DM, Allsopp N, D'Antonio CM, Milton SJ, Rejmanek M (2000) Plant invasions - the role of mutualisms. Biol Rev 75:65-93

Ringel MS, Hu HH, Anderson G (1996) The stability and persistence of mutualisms embedded in community interactions. Theor Popul Biol 50:281-297 
Seifert KA (1993) Sapstain of commercial lumber by species of ophiostoma and ceratocystis. In: Wingfield MJ, Seifert KA, Webber JF (eds) Ceratocystis and ophiostoma: taxonomy, ecology and pathogenicity. American Phytopathology Press, St. Paul, pp 141-151

Six DL, Paine TD (1998) Effects of mycangial fungi and host tree species on progeny survival and emergence of Dendroctonus ponderosae (Coleoptera: Scolytidae). Environ Entomol 27:1393-1401

Solheim H (1986) Species of Ophiostomataceae isolated from Picea abies infested by the bark beetle Ips typographus. Nord J Bot 6:199-207

Stanton ML (2003) Interacting guilds: moving beyond the pairwise perspective of mutualisms. Am Nat 162:S10-S23

Strobel GA, Lanier GN (1981) Dutch elm disease. Sci Am 245:4050

Thatcher RC, Searcy JL, Coster JE, Hertel GD (1980) The southern pine beetle. Technical Bulletin 1631, United States Department of Agriculture Forest Service, Combined Forest Pest Reserch and Development Program, Pineville, LA. $267 \mathrm{pp}$

Turchin P, Lorio PL, Taylor AD, Billings RF (1991) Why do populations of southern pine beetles (Coleoptera: Scolytidae) fluctuate? Environ Entomol 20:401-409
Turchin P, Taylor AD (1992) Complex dynamics in ecological time series. Ecology 73:289-305

Turchin P, Taylor AD, Reeve JD (1999) Dynamical role of predators in population cycles of a forest insect: an experimental test. Science 285:1068-1071

Ungerer MJ, Ayres MP, Lombardero MJ (1999) Climate and the northern distribution limits of Dendroctonus frontalis Zimmermann (Coleoptera: Scolytidae). J Biogeog 26:1133-1145

Waser NW, Price MV, Brody AK, Campbell DR (2000) Pollination success and plant population size: how strong are the links? Bull Ecol Soc Am 85:S227

Wilson DS (1986) Adaptive indirect effects. In: Diamond J, Case T (eds) Community ecology. Harper and Row, New York, pp 437-444

Wootton JT (1993) Indirect effects and habitat use in an intertidal community: interaction chains and interaction modifications. Am Nat 141:71-89

Wullschlager SD, McLaughlin SB, Ayres MP (2004) High-resolution analysis of stem increment and sap flow for loblolly pine trees attacked by southern pine beetle. Can J For Res 34: (in press)

Yearian WC, Gouger RJ, Wilkinson RC (1972) Effects of the bluestain fungus, Ceratocystis ips, on development of Ips bark beetles in pine bolts. Annu Entomol Soc Am 65:481-48 